\title{
TOPICAL ANESTHESIA: H-REFLEX RECOVERY CHANGES BY DESENSITIZATION OF THE SKIN
}

\author{
M. SABBAHI ${ }^{a, b}$ and C.J. DE LUCA ${ }^{b, c}$ \\ - Department of Health Sciences, Sargent College of Allied Health Professions, Boston University, Boston, Mass., \\ b Liberty Mutual Research Center, Hopkinton, Mass., and ' Neuromuscular Research Laboratory, Department of \\ Orthopaedic Surgery, Harvard Medical School, Children's Hospital Medical Center, Boston, Mass. 02115 (U.S.A.)
}

(Accepted for publication: May 9, 1981)

H-reflex recovery curves have often been used clinically to measure the excitability of the motoneuron pool. However, such curves have often been difficult to interpret clinically (Matthews 1970).

Their reliability as a clinical indicator of the excitability of the $\alpha$-motoneuron pool is marred, however, by a number of variables that influence the H-reflex. Among the parameters that have been postulated to affect the H-reflex recovery are the following: (1) inhibition of the motoneuron pool by group II afferent volley via internuncial activity (Magladery et al. 1951); (2) recurrent inhibition by Renshaw cells that may cause the primary inhibition period, especially in its earliest part (Haase et al. 1975); (3) impulses from $1 \mathrm{~b}$ afferents that may have a similar effect (Hufschmidt 1966); (4) feedback from the muscle spindles and joint receptors leading to inhibition (Táboríková and Sax 1969); (5) some supraspinal mechanism (Táboŕiková 1973); and (6) depletion of the transmitter substances at the 1a- $\alpha$-motoneuron synapses by the conditioning stimulus (Tábori íková and Sax 1969).

In the present paper we add to this list a parameter that has not previously been shown to have an influence on the H-reflex recovery curve, namely, the input from afferent nerves located in the skin. Previous studies (Gassel and Ott 1970) have shown that electrical and noxious stimulation of the skin affects the amplitude of the H-reflex, but to our knowl- edge no study has thus far shown the effect of natural or on-going discharge by the afferent nerves in the skin on recovery curves for the H-reflex. The fact that we used topical anesthesia to desensitize the skin receptors rather than noxious stimuli renders this investigation more appropriate for studying the natural stimuli that typically affect the H-reflex in ordinary non-experimental conditions. Some of our measurements differentiate between dermatomes and others, between more general areas pertaining to the calf, tibialis anterior, quadriceps, and ham. strings locations.

\section{Material and methods}

In measuring an H-reflex recovery curve, an initial electrical pulse elicits an $\mathrm{H}$-reflex $\left(\mathrm{H}_{1}\right)$ and the time delay that occurs before another pulse of the same intensity can elicit another H-reflex $\left(\mathrm{H}_{2}\right)$ is measured. The amplitudes of the two reflexes are measured and compared. At times it is also useful to monitor the gradual increase in amplitude of the $\mathrm{H}_{2}$ reflexes as a function of time between pulses.

A total of 53 adult subjects whose age ranged from 18 to 52 years with a mean of $27 \pm 7$ were tested for the effect of topical anesthesia after giving their informed consent. All subjects were without past history of neurological conditions. They were asked to lie prone in a relaxed and comfortable posi- 


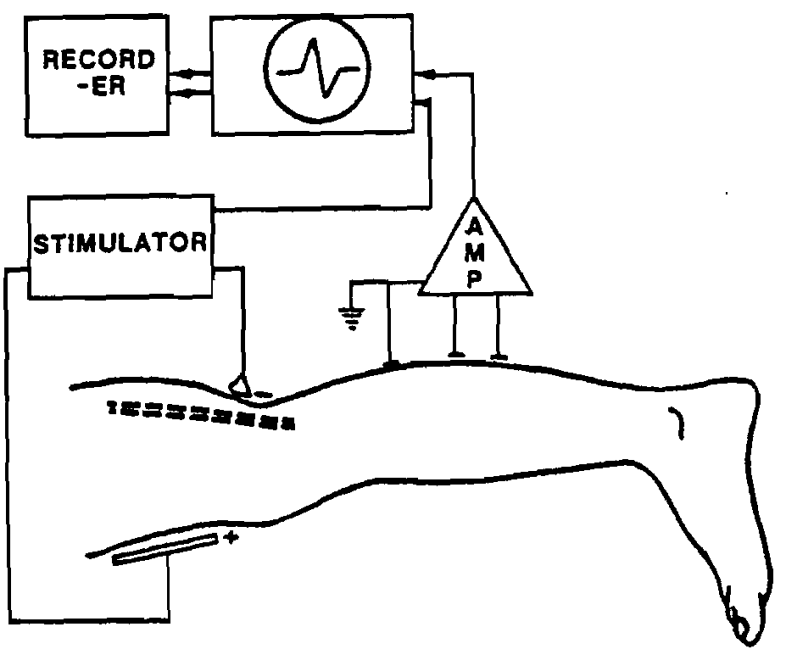

Fig. 1. The experimental set-up for recording the H-reflex.

tion while the ankle was secured in a specially designed apparatus which allowed the foot to move freely during reflex contraction of the muscles. A diagram of the recording set-up is shown in Fig. 1.

The H-reflex was elicited by stimulating the posterior tibial nerve unifocally with $1 \mathrm{msec}$ square pulse once every $5 \mathrm{sec}$ with a stimulus that was subthreshold to the muscle action potential response (M-wave). The stimulation electrode (cathode) consisted of a felt sphere $1.5 \mathrm{~cm}$ in diameter soaked with $0.9 \%$ physiological saline solution. The indifferent elec. trode (anode) for stimulation consisted of a $10 \mathrm{~cm} \times 10 \mathrm{~cm}$ cotton-padded mesh soaked in $0.9 \%$ physiological saline and placed on the anterior surface of the thigh just above the patella. The H-response was recorded differentially via two cup electrodes coated with gel that were placed $3 \mathrm{~cm}$ apart on the skin overlying the soleus muscle and in line with the Achilles tendon. The indifferent electrode for recording was a rectangular metal plate (3 $\mathrm{cm} \times 5 \mathrm{~cm}$ ) placed between the stimulation and recording sites to minimize the stimulus artifact. The signal was amplified 1000 times with a bandwidth of $10 \mathrm{~Hz}$ to $10 \mathrm{kHz}$, and was subsequently preserved on an ultraviolet. sensitive paper for analysis.
At the beginning of each experiment the amplitude of the H-reflex was stabilized by using the method of Sabbahi and De Luca (in preparation). This was achieved by using a threshold stimulus to the muscle response with a frequency of 1 pulse/sec for $3 \mathrm{~min}$, then lowering the stimulus frequency gradu. ally to 0.5 pulse $/ \mathrm{sec}$, and finally to 0.2 pulse/ $\mathrm{sec}$, while at the same time reducing the stimulus intensity until an appropriate H-reflex amplitude with minimum variability was obtained. Stimulation every $5 \mathrm{sec}$ using the selected stimulus intensity was continued until maximum stabilization of the H-reflex amplitude was achieved (this generally took 3-5 $\mathrm{min}$ ) at which point the experiment could begin. This was achieved when the stimuli for the $\mathrm{H}$-reflexes were subliminal to the M-wave, and elicited approximately $70 \%$ of the maximal amplitude of the H-reflex. H-reflex recovery was then tested by varying the interstimulus intervals, while keeping the stimulus intensity constant.

After measuring the control recovery of $\mathrm{H}_{2}$ for incremented interstimulus intervals, topical anesthesia (20\% benzocaine) was sprayed for 15-20 sec on one of the following 4 skin areas for each subject: the calf skin area, the tibialis anterior area, the quadriceps skin area and the hamstrings skin area. In 3 subjects the total skin area of the lower limb was anesthetized to test any summation effect on the motoneuron pool. The topical anesthesia was also sprayed on one of the following skin dermatomes for each subject: $\mathrm{L}_{2}, \mathrm{~L}_{3}, \mathrm{~L}_{4}, \mathrm{~L}_{5}$, $\mathbf{S}_{1}, \mathrm{~S}_{2}$. The recovery of the H-reflex was tested $30 \mathrm{~min}$ after application of the anesthesia in all subjects and was compared to the control recovery before anesthesia. In 17 subjects H-reflex recovery was also tested 15 min after anesthesia.

Three subjects were tested, using the same procedure, while a placebo spray was used. The placebo spray was a product containing all the ingredients of the active spray except the benzocaine. These control experiments were conducted without prior information given to the subjects. 
Results

In this study the initial recovery time refers to the period during which the smallest detectable $\mathrm{H}_{2}$-reflex can be elicited by a pulse identical to the one that had just elicited an $\mathrm{H}_{1}$-reflex. The degree of recovery at a specific interstimulus interval refers to the ratio of the peak-to-peak amplitude of the $\mathrm{H}_{2}$ - to the $\mathrm{H}_{1}$-reflex at that particular interval and is expressed as a percentage.

Before the application of anesthesia, the initial recovery time varied among subjects, ranging from 35 to $100 \mathrm{msec}$ (Fig. 2). As the interstimulus interval increased, more subjects gradually recovered from the primary inhibition period. Before anesthesia 3 subjects did not show recovery within the $100 \mathrm{msec}$ inter$\mathrm{val}$, whereas after anesthesia only 1 subject did not show recovery in this time period.

Ten minutes after application of topical anesthesia to the skin most subjects reported a slight reduction of skin sensation to superficial touch and hair movements with preservation of other sensation. This effect lasted throughout the duration of the experiment.

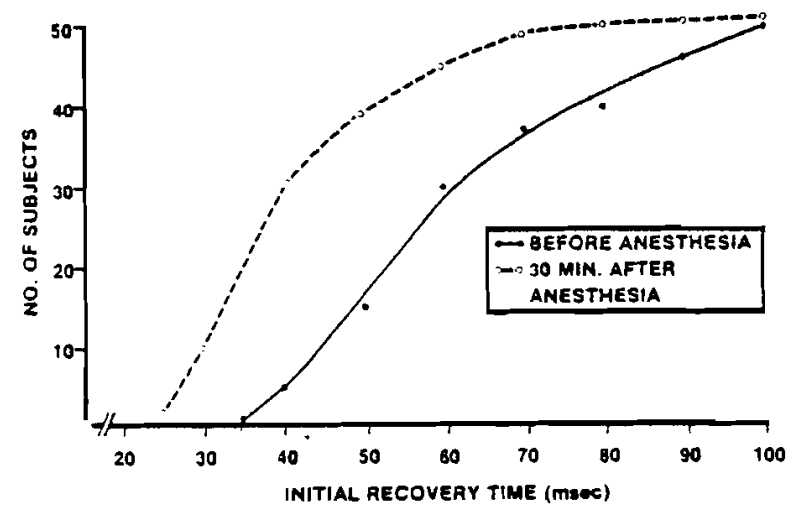

Fig. 2. The initial recovery time of the H-reflex, in all subjects, before the application of the topical anesthesia (solid line) was distributed along a wide range of interstimulus intervals. The initial recovery time was reduced substantially $30 \mathrm{~min}$ after application of topical anesthesia (dashed line) to various skin areas and dermatomes. The curves represent a cumulative distribution of the number of subjects.
(This reduced sensation was not reported by the subjects when they were sprayed with the placebo.)

Thirty minutes after topical anesthesia was applied to the various skin areas and dermatomes the initial recovery time decreased by $20 \pm 17 \mathrm{msec}$ in 42 out of 53 subjects (Fig. 2). Eleven subjects, however, showed no measurable change in the initial recovery time after anesthesia. It is speculated that in these subjects the topical anesthesia did not effectively desensitize the cutaneous receptors (especially in those subjects who felt no substantial changes in their skin sensation). It can be seen that after anesthesia $92 \%$ of the subjects recovered their $\mathrm{H}$-reflex when the $\mathrm{H}_{1}$ to $\mathrm{H}_{2}$ interval was $70 \mathrm{msec}$, whereas without anesthesia only $70 \%$ of the subjects were able to produce an $\mathrm{H}_{2}$-reflex after that interval of time. At the interstimulus interval of $50 \mathrm{msec}$,

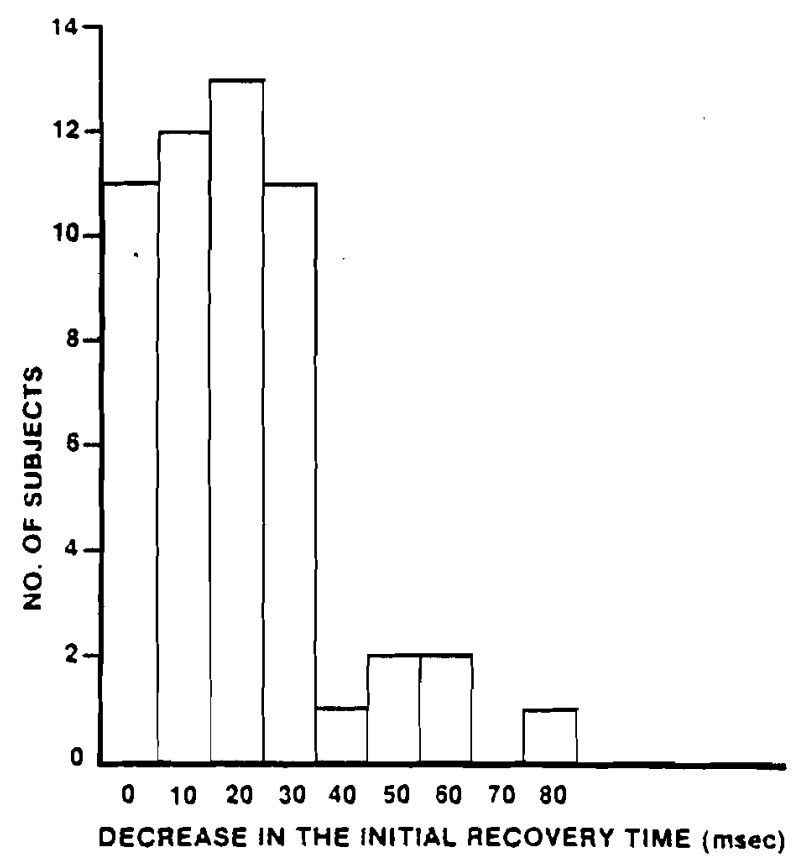

Fig. 3. The decrease in the initial recovery due to the application of topical anesthesia varied among subjects. Most subjects showed an H-reflex recovery that occurred 10-30 msec earlier, after the application of anesthesia. Eleven subjects showed no measurable changes. 
the difference between groups is even more striking: $74 \%$ of the subjects after anesthesia produced $\mathrm{H}_{2}$-reflexes compared with only $26 \%$ prior to anesthesia.

It was also noted as a separate observation that after anesthesia was applied to the various skin areas and dermatomes, the peak-topeak amplitude of the H-reflex showed significant $(P<0.001)$ facilitation in every case except for the skin overlying the anterior tibial muscle and the $S_{1}$ dermatome. In order to monitor the changes in the stimulus volley, the $\mathrm{M}$-wave was occasionally checked. No measurable changes were noticed throughout the experiment. The details of this interesting observation will be reported in another publication (Sabbahi and De Luca, in preparation).

The extent of H-reflex initial recovery shift as a result of anesthesia varies from one subject to another. Most subjects recovered 10$30 \mathrm{msec}$ earlier after the application of the anesthesia (Fig. 3). However, in one subject the initial recovery time decreased by more than 70 msec. In the control series of reflex recovery for this particular subject, no H-reflex recovery was noted until the 100 msec interstimulus interval was reached, an indication of exceptionally strong H-reflex inhibition. After the application of topical anesthesia to the $\mathrm{L}_{4}$ dermatome of this sub-

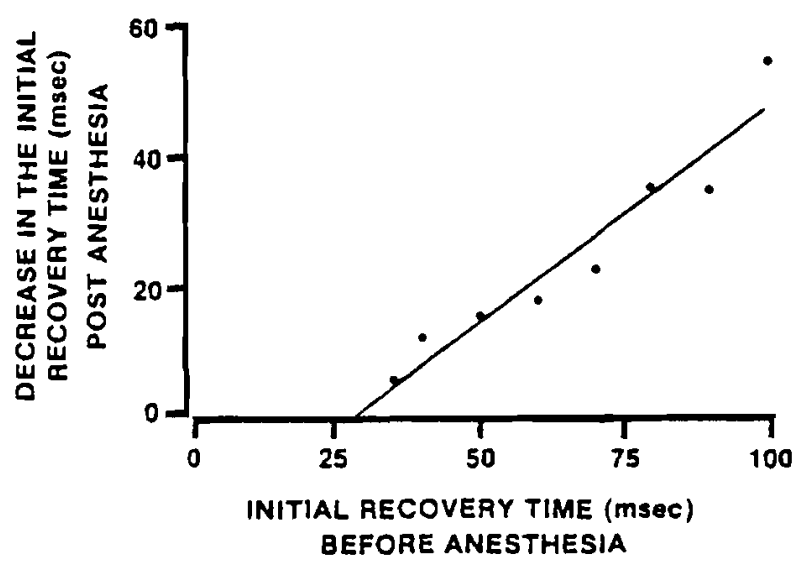

Fig. 4. The amount of average decrease in time required to elicit an $\mathrm{H}_{2}$-reflex after the application of anesthesia is directly related to the amount of time required for the initial recovery (before anesthesia). ject, the H-reflex started to recover after an interstimulus interval of $30 \mathrm{msec}$.

In keeping with these results, the average decrease in the initial recovery time noted after the application of the anesthesia was plotted against the initial recovery time (Fig. 4). A linear regression analysis revealed the following relationship:

$y=18.5+0.66 x$ for $28 \leqslant x \leqslant 100$,

where $y=$ the decrease in the initial recovery
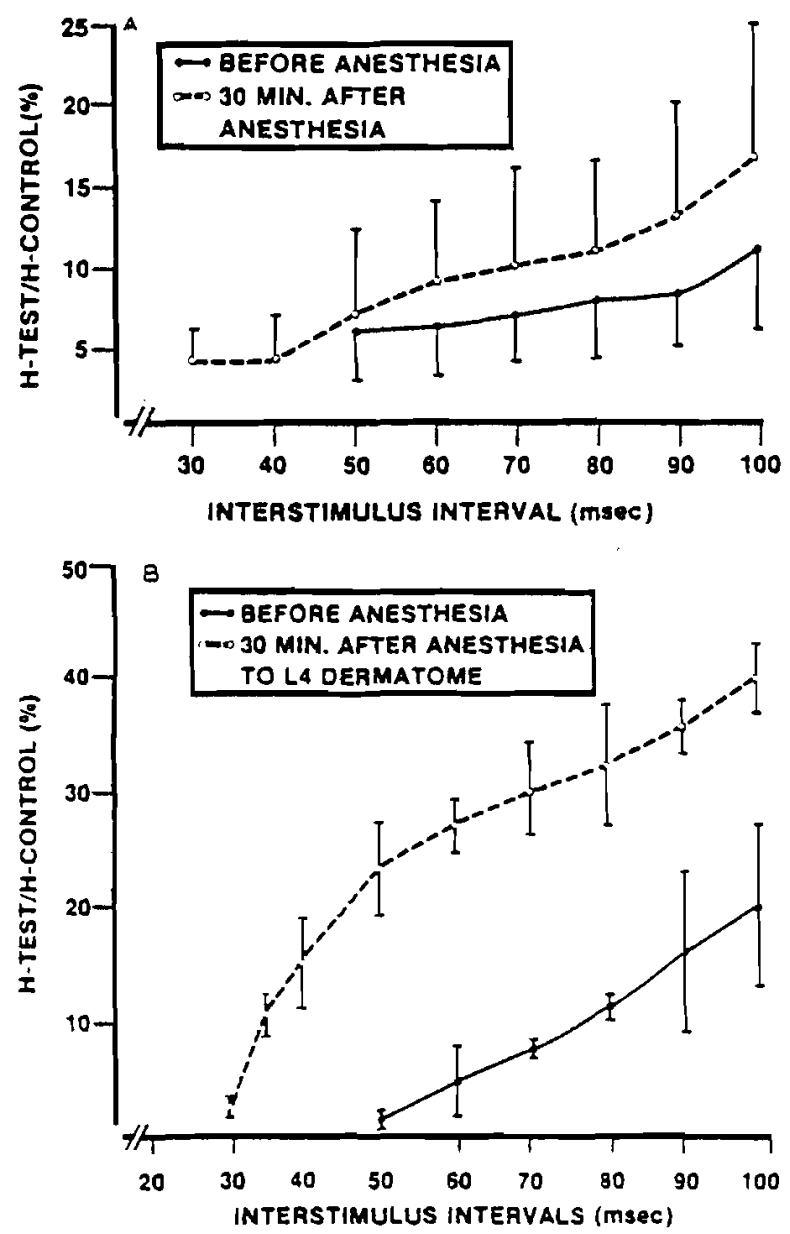

Fig. 5. A: the grand mean of the degree of recovery of the H-reflex versus time of interstimulus intervais (recovery curve) before (solid) and $30 \mathrm{~min}$ after (dashed) application of topical anesthesia to different skin areas and dermatomes. B: a sample recovery curve for one subject before (solid) and $30 \mathrm{~min}$ after (dashed) application of topical anesthesia to $\mathrm{L}_{4}$ dermatome. The mean of 5 consecutive sweeps and 1 S.D. are shown. 
time post-anesthesia in $\mathrm{msec}$ and $\mathrm{x}=$ the initial recovery time before anesthesia in msec. The correlation coefficient was $r=$ 0.96 . Thus the larger the initial recovery time before anesthesia, the more it decreased following anesthesia.

After the initial recovery was achieved, the $\mathrm{H}_{2}$-reflex gradually increased in amplitude when the interstimulus interval was increased up to $100 \mathrm{msec}$, the maximal interstimulus interval used (Fig. 5A and $\mathrm{B}$ ). The degree of recovery with time also varied among sub. jects, although the pattern of a gradual incrementation of the H-reflex was similar in all subjects. Fig. 5A shows the mean recovery curve before and $30 \mathrm{~min}$ after application of topical anesthesia to the different skin areas and dermatomes. The $\mathrm{H}$-reflex recovery at $100 \mathrm{msec}$ varied for $0.3-22 \%$ of the H-reflex responses with a mean value of $10.6 \% \pm 5 \%$.

As may be seen in Fig. 2, before application of the anesthesia, 15 subjects showed initial recovery after $50 \mathrm{msec}$, whereas $30 \mathrm{~min}$ after anesthesia, 10 subjects showed initial recovery of the test reflex at $30 \mathrm{msec}$. These initial recovery times were used as the grand mean initial recovery for all subjects tested before and after anesthesia (Fig. 5A). In Fig. $5 \mathrm{~A}$ it may be seen that not only the test H-reflex recovered earlier after anesthesia, but with increasing interstimulus intervals, it showed a faster and steeper recovery. This faster and steeper recovery was statistically significant $(P<0.01$ at $60 \mathrm{msec}$ to $P<$ 0.0003 at $100 \mathrm{msec}$ ) in all subjects after anesthesia.

Although intersubjects variation was relatively large which partially masked the issue, the faster recovery was even more striking and distinguishable in individual experiments. In the individual recovery curve shown in Fig. $5 \mathrm{~B}$, the $\mathrm{H}_{2}$-reflex showed an earlier and more substantial recovery $30 \mathrm{~min}$ after application of topical anesthesia to the $\mathrm{L}_{4}$ dermatome as compared to the control H-reflex recovery.

The extent to which the initial recovery time was shortened following anesthesia had no apparent correlation with the skin area or dermatome desensitized by the anesthesia. When the initial recovery time before and 30 min after application of topical anesthesia was recorded, no measurable differences were noticed between different skin areas and dermatomes. Furthermore, it is interesting to note that when the total skin area of the lower limb was desensitized, no summation effect on the initial recovery was noticed.

Although most of the tests for the effects of anesthesia were carried out $30 \mathrm{~min}$ after its administration, in 17 subjects the H-reflex recovery was also measured at $15 \mathrm{~min}$ after applying the anesthesia, and in 3 subjects at various intervals between 30 and $60 \mathrm{~min}$ after its application. In these 20 subjects the change in the initial recovery time increased with time post anesthesia. This observation is consistent with the previously mentioned increase in amplitude of the $\mathrm{H}$-reflex with time post anesthesia.

In general, significant facilitation in the H-reflex amplitude was always associated with substantial changes in the recovery curves. Correspondingly, those subjects who showed reflex inhibition or no significant change in amplitude of the H-reflex after application of the anesthesia to the anterior tibial skin or $\mathrm{S}_{1}$ dermatome also showed no significant changes in the H-reflex recovery curves. None of the above-mentioned changes in the recovery curves were noticed after the placebo spray was applied to the skin of the lower limb.

\section{Discussion}

The pattern of recovery of the $\alpha$-motoneuron pool observed in this study was similar to that which has been previously reported in the literature (Hayes et al. 1979; Paillard 1959). Specifically, the period of inhibition following an $\mathrm{H}_{1}$-reflex and the general correlation of the incrementing amplitude of the $\mathrm{H}_{2}$ reflex with increased interstimulus interval have been reported by other investigators. Moreover, an abnormally quick recovery 
period for the H-reflex following upper motoneuron lesion was reported almost 3 decades ago (Magladery et al. 1952) and was attributed to an increase in the excitability of the motoneuron pool after a CNS lesion. Correspondingly, slower recovery was noticed with decreased excitability of the motoneuron pool in spinal shock and cerebellar syndrome (Olsen and Diamantopoulos 1967; GarciaMulin and Mayer 1972).

The faster recovery period after the application of topical anesthesia to the skin is most likely due to increased excitability of the motoneuron pool in response to reduced inputs from cutaneous afferents. Hagbarth (1960) demonstrated that certain skin areas are excitatory while others are inhibitory to the extensor motoneuron pool. Our results indicate that the cutaneous afferent input plays an important inhibitory role on the $\alpha$-motoneuron pool of the soleus muscle. This point is supported by a companion investigation by Sabbahi and De Luca (in preparation).

From the results of this study, it is not pos. sible to ascertain which mechanism caused the observed increase in the $\alpha$-motoneuron pool excitability when the cutaneous receptors were desensitized. Both segmental and suprasegmental effects may be involved. Input from cutaneous afferents appears to have a substantial effect throughout the early part of the recovery period, i.e., up to $100 \mathrm{msec}$. Within this time frame, the long-loop supraspinal input could be involved (Táboríkpva 1973), and it is perhaps this mechanism that is influenced by input from cutaneous afferents (Gassel and Ott 1970). There would be sufficient time for the inhibitory supra. spinal pathways to be activated by the spinal input which is activated by the cutaneous afferents. However, segmental influences cannot be totally excluded.

The facilitation noticed in this study in the H-reflex recovery curve occurs at $30-100$ msec of interstimulus intervals. Caccia et al. (1973) reported that during such time the EMG activity of the abductor pollicis brevis was inhibited by cutaneous reflexes as induced by electrical stimuli to the index finger. The TVR of the calf muscle has also been shown to be inhibited after application of topical anesthesia to the skin overlying the muscle (Abbruzzese et al. 1978). The inhibition period reported by Caccia's group was noticed $30-80 \mathrm{msec}$ after the induced stimulus. They reported an initial inhibition period which was attributed to the effect of the small myelinated nociceptor fibers (which are reportedly responsible for the inhibitory postsynaptic potential), while the second inhibition period was accounted for by the inhibitory mechanisms of the slowly conducting fusimotor system. Skin desensitization with topical anesthesia may result in reduction of this cutaneous inhibitory effect on the excitability of the $\alpha$-motoneurons and may account for the changes noticed in our study.

The discharge of the motoneuron pool in response to afferent signals has been reported to be modulated by supraspinal inputs. Willer et al. (1979) demonstrated an alternation in the flexion nociceptive reflex by supraspinal inflow as set by mental task or stress. Also, the long latency stretch reflex, but not the tendon reflex, of the flexors of the thumb was inhibited by deep anesthesia to the thumb (Marsden et al. 1979). However, this was not the case when the anesthesia was applied to the foot or the great toe (Marsden et al. 1977). In an earlier investigation, Marsden et al. (1976) proposed a tentative hypothesis that cutaneous afferents may have a tonic facilitory effect on the cortex. This was based on the findings of Rosen and Asanuma (1972) that cutaneous afferents demonstrated abundant projection to the motor cortex. Moreover, the firing discharge of the pyramidal tract neurons was increased after blocking of the afferent inputs by a small dose of anesthesia (Lewis and Porter 1974).

It may be seen in Fig. 4 that subjects whose $\alpha$-motoneurons had a relatively longer initial recovery time demonstrated a relatively greater decrease in the initial recovery time after the application of anesthesia to the skin. It has been shown in previous investigations 
that tonic motoneurons tend to have a faster H-reflex recovery time than phasic motoneurons (Sabbahi Awadalla 1976; Sabbahi and Sedgwick 1979) as well as faster firing rates (Kernell 1965). Hence, it appears that some $\alpha$-motoneurons are more driven by skin inputs than are other motoneurons, a point that has been previously suggested by Burke (1973) and Kanda et al. (1977). However, more studies need to be done to support this conjecture.

In conclusion, our results demonstrate that input from cutaneous afferents may have an important inhibitory influence on the excitability of the soleus $\alpha$-motoneuron pool, possibly via segmental and supraspinal long-loop pathways. Thus, if the H-reflex recovery curves are to be used as a clinical tool, it is important to keep in mind that changes in cutaneous afferent inputs, such as those that might be caused by lesions, for example, need to be considered in interpreting the observed data.

\section{Summary}

The H-reflex recovery curve of the soleus muscle was studied in 53 normal subjects before and after the application of topical anesthesia ( $20 \%$ benzocaine) to various skin areas and dermatomes of the lower limb. Skin areas were those overlying the calf, tibialis anterior, quadriceps and hamstrings muscles, and the dermatomes were $\mathrm{L}_{2}, \mathrm{~L}_{3}, \mathrm{~L}_{4}, \mathrm{~L}_{5}, \mathrm{~S}_{1}$, $\mathrm{S}_{2}$. In 42 subjects the $\mathrm{H}$-reflex initial recovery decreased by $10-80 \mathrm{msec}$ with a mean of $20 \pm 17 \mathrm{msec} 30 \mathrm{~min}$ after application of the topical anesthesia. Also, the test reflex (the second sequential H-reflex) had a faster recovery with less inhibition than that before anesthesia. It was also noticed that the longer the inhibition period before anesthesia, the greater the decrease in recovery time. These observations had no correlation with the skin area or dermatome desensitized by the anesthesia. Furthermore, these observations were not noted when a placebo was sprayed on the skin.

The results from this study indicate that input from cutaneous afferents may have an important inhibitory effect on the $\alpha$-motoneurons of the soleus muscle. This effect is possibly more profound on the large phasic motoneurons. These results are discussed in relation to clinical interpretations of the H-reflex recovery curves.

\section{Résumé}

Anesthésie topique: modifications de la récupération du réflexe-H par désensibilisation de la peau

La courbe de récupération du réflexe $-\mathrm{H}$ du muscle soléaire est étudiée chez 53 sujets normaux avant et après application d'anesthésie topique (20\% de benzocaïne) à diverses aires de la peau et aux dermatomes du membre inférieur. Les aires cutanées sont celles qui recouvrent les muscles de la jambe, tibial antérieur, quadriceps et du mollet et les dermatomes sont $\mathrm{L}_{2}, \mathrm{~L}_{3}, \mathrm{~L}_{4}, \mathrm{~L}_{5}, \mathrm{~S}_{1}, \mathrm{~S}_{2}$. Chez 42 sujets, la récupération initiale du réflex- $\mathrm{H}$ diminue de 10 à $80 \mathrm{msec}$ avec une moyenne de $20 \pm 17 \mathrm{msec}, 30 \mathrm{~min}$ après application topique de l'anesthésie. De même, le réflexe test (le second réflexe- $H$ séquentiel) a une récupération plus rapide avec moindre inhibition qu'avant l'anesthésie. On note également que plus la période d'inhibition avant l'anesthésie est longue, plus importante est la diminution du temps de récupération. Ces observations n'ont pas de corrélation avec l'aire cutanée ou le dermatome désensibilisés par l'anesthésie. En outre, ces résultats ne s'observent pas lorsque un placebo est vaporisé sur la peau.

Les résultats de cette étude indiquent que l'entrée venant d'afférences cutanées peut avoir un effet inhibiteur important sur les motoneurones alpha du muscle soléaire. Cet effet est peut-être plus profond sur les grands motoneurons phasiques. Ces résultats sont discutés par rapport aux interprétations cliniques des courbes de récupération du réflexe-H.

The autliors are grateful for the interest and assistance provided by Dr. W.R. Powers throughout this study. The topical anesthesia spray (Americaine) as well as the placebo spray were supplied by American 
Critical Care. This work was supported by Liberty Mutual Insurance Company and a Project Hope grant to M. Sabbahi.

\section{References}

Abbruzzese, G., Hagbarth, K.E., Homma, I. and Wallin, U. Excitation from skin receptors contributing to the tonic vibration reflex in man. Brain Res., 1978, 150: 194-197.

Burke, R.E. On the central nerrous system control of fast and slow twitch motor units. In: J. Desmedt (Ed.), New Develop. EMG Clin. Neurophysiol., Vol. III. Karger, Basel, 1973: 69-94.

Caccia, M.R., McComas, A.J., Upton, A.R.M. and Blogg, T. Cutaneous reflexes in small muscles of the hand. J. Neurol. Neurosurg. Psychiat., 1973, 36: $960-977$.

Garcia-Mullin, R. and Mayer, R.F. Acute and chronic hemiplegia, H-reflex studies. Brain, 1972, 95 : 559-572.

Gassel, M.M. and Ott, K.M. Local sign and late effects on motoneuron excitability of cutaneous stimula. tion in man. Brain, 1970, 93: 95-106.

Haase, J., Cleveland, S, and Ross, H.G. Problems of post-synaptic autogenous and recurrent inhibition in the mammalian spinal cord. Rev. Physiol. Biochem. Pharmacol., 1975, 73: 73-129.

Hagbarth, K.E. Spinal withdrawal reflexes in the human lower limbs. J. Neurol Neurosurg. Psychiat., 1960, 23 : 222-227.

Hayes, K.C., Robinson, K.L., Wood, G.A. and Jen. nings, L.S. Assessment of the H-reflex excitability curve using a cubic spline function. Electroenceph. clin. Neurophysiol., 1979, 46: 114-117.

Hufschmidt, H.J. The demonstration of autogenic inhibition and its significance in human voluntary movement. In: R. Granit (Ed.), Muscular Afferent and Motor Control, Nobel Symposium I. Almquist and Wiksell, Stockholm, 1966: 269-274.

Kanda, K., Burke, R.E. and Walmsley, B. Differential control of fast and slow twitch motor units in the decerebrate cat. Exp. Brain Res., 1977, 29: 5774.

Kernell, D. The limits of firing frequency in cat lumbosacral motoneurons possessing different time course of afterhyperpolarization. Acta physiol. scand., 1965, 65: 87-100.

Lewis, M. McD. and Porter, R. Pyramidal tract discharge in relation to movement performance in monkeys with partial anesthesia of the moving hand. Brain Res., 1974, 71: 345-351.

Magladery, J.W., Teasdall, R.D., Park, A.M. and Porter, W.E. Electrophysiological studies of nerve and reflex activity in normal man. Excitation and inhibition of two neuron reflexes by afferent im- pulses in the same nerve trunk. Bull. Johns Hopk. Hosp., 1951, 88: 520-537.

Magladery, J.W., Teasdale, R.D. and Park, A.M. Electrophysiological studies of reflex activity in patients with lesions of the nervous system. A comparison of spinal motoneuron excitability following afferent nerve volleys in normal persons and patients with upper motor neuron lesions. Bull. Johns Hopk. Hosp., 1952, 91: 219-244.

Marsden, C.D., Merton, P.A. and Morton, H.B. Servo action in the human thumb. J. Physiol. (Lond.), 1976, 257: 1-44.

Marsden, C.D., Merton, P.A. and Morton, H.B. The sensory mechanism of servo action in human muscle. J. Physiol. (Lond.), 1977, 265: 521-535.

Marsden, C.D., Rothwell, J.C. and Traub, M.M. Effect of thumb anesthesia on weight perception, muscle activity and the stretch reflex in man. J. Physiol. (Lond.), 1979, 294: 303-315.

Matthews, W.B. The clinical implications of the H-reflex and other electrically induced reflexes. In: D. Williams (Ed.), Modern Trends of Neurology, Vol. 5, Butterworths, London, 1970: 241253.

Olsen, Z.P. and Diamantopoulos, E. Excitability of spinal motoneurons in normal subjects and patients with spasticity, parkinsonian rigidity and cerebellar hypotonia. J. Neurol. Neurosurg. Psychiat., 1967, 30: 325-331.

Paillard, J. Functional organization of afferent innervation of muscle studies in man by monosynaptic testing. Amer. J. phys. Med., 1959, 38: 239-247.

Rosen, I. and Asanuma, H. Peripheral afferent inputs to the forelimb area of the monkey motor cortex: input-output relations. Exp. Brain Res., 1972, 14: 257-273.

Sabbahi Awadalla, M.A., Motoneuron and Monosynaptic Reflex Excitability Studies in Man, Ph.D. Thesis. University of Southampton, U.K., 1976: 190-222.

Sabbahi, M.A. and De Luca, C.J. Topical anesthesia: modulation of the monosynaptic reflexes by desensitization of the skin. Submitted for publication to Electroenceph. clin. Neurophysiol.

Sabbahi, M.A. and Sedgwick, M.S. H-reflex recovery curve - single fiber EMG studies. In: Proc. 4 th Congr. Int. Soc. Electrophysiological Kinesiology, Boston, Mass., 1979: 188-189.

Tábořlková, $\mathrm{H}$., Supraspinal influences on $\mathrm{H} \cdot$-reflexes. In: J. Desmedt (Ed.), New Development in EMG. Clin. Neurophysiol., Vol. III. Karger, Basel, 1973: $328-335$.

Táboříková, $H$. and Sax, D. Conditioning of H-reflexes by a preceding subthreshold H-reflex. Brain, 1969, 92 : 203-212.

Willer, J.C., Boureau, F. and Albe-Fessard, D. Supraspinal influences on nociceptive flexion reflex and pain sensation in man. Brain Res., 1979, 179:6168. 